\title{
Structure and Electrochemical Properties of Porous Material Based on Aspen Wood
}

\author{
Svetlana I. Tsyganova*, \\ Alexander S. Romanchenko, Olga Yu. Fetisova, \\ Elena V. Mazurova and Galina N. Bondarenko \\ Institute of Chemistry and Chemical Technology SB RAS \\ FRC "Krasnoyarsk Science Center SB RAS" \\ 50/24 Akademgorodok, Krasnoyarsk, 660036, Russia
}

Received 16.04.2018, received in revised form 04.05.2018, accepted 03.06.2018

The structure and electrochemical properties of the products of the thermochemical transformation of aspen modified and unmodified with zinc chloride have been studied. It is shown that the addition of $\mathrm{ZnCl}_{2}$ to the lignin-cellulose mass leads to a significant increase of the specific surface area of the carbonized product up to $1800 \mathrm{~m}^{2} \cdot \mathrm{g}^{-1}$ and the formation of $\mathrm{ZnO}$ crystalline phase.

The influence of the conditions of material synthesis and electrolyte concentration (1M and $3 \mathrm{M} \mathrm{KOH})$ on the shape of voltammetric curves is revealed by cyclic voltammetry. It is established that aspen wood after prolonged exposure in water can be successfully used to produce porous carbon electrode materials.

Keywords: synthesis, aspen wood, carbon-containing composite, zinc chloride, specific surface, structure, cyclic voltammetry.

Citation: Tsyganova S.I., Romanchenko A.S., Fetisova O.Yu., Mazurova E.V., Bondarenko G.N. Structure and electrochemical properties of porous material based on aspen wood, J. Sib. Fed. Univ. Chem., 2018, 11(2), 281-290. DOI: 10.17516/1998-28360075 .

(C) Siberian Federal University. All rights reserved

* Corresponding author E-mail address: light@icct.ru 


\title{
Структура и электрохимические свойства пористого материала на основе древесины осины
}

\author{
С.И. Цыганова, А.С. Романченко, \\ О.Ю. Фетисова, Е.В. Мазурова, Г.Н. Бондаренко \\ Институт химии и химической технологии СО РАН \\ ФИЦ «Красноярский научный центтр СО РАН» \\ Россия, 660036, Красноярск, Академгородок, 50/24
}

Исследовань структура и электрохимические свойства продуктов термохимического превращцения опилок осины, модифицированных и немодифицированных хлоридом цุинка. Показано, что добавка $\mathrm{ZnCl}_{2}$ в лигниноцеллюлозную массу приводит к существенному росту удельной поверхности карбонизованного продукта до $1800 \mathrm{M}^{2} \mathrm{2}^{-1}$ и образованию кристаллической фазы $\mathrm{ZnO}$.

С помощьью цุиклической вольтамперометрии выявлено влияние условий синтеза материала и концентрации электролита (1M и 3М КОН) на форму вольтамперометрических кривых. Установлено, что древесина осины после длительной выдержки в воде может быть успешно использована для получения пористых углеродных электродных материалов.

Ключевые слова: синтез, древесина осины, углеродсодержащий композит, хлорид цุинка, удельная поверхность, структура, циклическая вольтамперометрия.

\section{Введение}

Создание новых типов пористых углеродных материалов (ПУМ) из дешевого природного сырья является актуальной задачей, учитывая постоянно возрастающие объемы использования ПУМ в качестве каталитических подложек, аккумуляторных электродов, конденсаторов, адсорбентов для хранения газов, а также в биомедицинской инженерии [1-5].

В этом ракурсе представляет интерес создание пористого композиционного материала на основе отходов осины, которая одна из самых распространенных на территории Российской Федерации (2-е место среди лиственных пород), быстрорастущая порода древесины, практически не используемая из-за заражения ее сердцевинной гнилью, высокой влажности, зольности, слабой механической прочности [6].

Эффективным методом получения пористого углеродистого материала из древесины служит химическая активация древесины хлоридом цинка с последующим пиролизом $[1,2]$, в результате которого можно получить наноструктурированные цинксодержащие композиционные материалы с высокой удельной поверхностью, имеющие широкий спектр применения в различных областях. Так, композиты на основе оксида цинка применяются для создания солнечных батарей, оптоэлектрических устройств, прозрачных электродов, а также газовых сенсоров, биосенсоров и суперконденсаторов [7-11]. Для получения подобных материалов, в основном, используют методы осаждения солей цинка (хлорида цинка или нитрата цинка) на 
предварительно приготовленную высокопористую подложку. Причем в качестве подложки применяют не только активированный углерод, получаемый в основном из скорлупы ореха и древесины березы, но и более дорогостоящие углеродные материалы типа углеродных волокон, нанотрубок, фуллеренов и др., требующих дорогостоящих операций [11-15]. Поэтому создание электродных материалов со специальными электрохимическими свойствами из низкосортной и низкотоварной древесины осины является перспективным, недорогим и экологическим направлением в области современных материалов.

Таким образом, цель настоящей работы заключается в исследовании процесса синтеза пористых материалов из опилок осины, подвергнутых длительной выдержке в воде, а также последующему модифицированию хлоридом цинка с выявлением структурной трансформации и электрохимических свойств продукта.

\section{Экспериментальная часть}

Исходным материалом для получения углеродсодержащих композитов служили опилки осины фракции менее 1,0 мм, полученные из среднестволовой части древесины осины. Опилки предварительно выдерживали в воде в течение двух месяцев, затем сепарировали и сушили до постоянного веса. Полученную массу пропитывали водным раствором хлорида цинка в массовом соотношении опилки: $\mathrm{ZnCl}_{2} 1: 1$; выдерживали в течении 4-5 ч и сушили до постоянного веса.

Образцы исходной древесины осины (ДО) и модифицированного хлоридом цинка (ДО$\mathrm{ZnCl}_{2}$ ) подвергали термохимическому превращению на горизонтальном проточном реакторе в инертной среде - в токе аргона, подаваемого со скоростью $130 \mathrm{~cm}^{3} \cdot$ мин $^{-1}$ до температур 400 и $800^{\circ} \mathrm{C}$ с выдержкой при конечной температуре 30 мин. Скорость нагрева составляла $10^{\circ} \mathrm{C}$ мин ${ }^{-1}$. Получаемый твердый продукт (ТП) промывали водой в течение 1,5 ч при температуре $60{ }^{\circ} \mathrm{C}$ до нейтральной среды с последующей сушкой до постоянного веса.

Удельную поверхность полученных продуктов измеряли методом тепловой десорбции азота на анализаторе «Газометр-1». Термический анализ образцов проводили на термоанализаторе STA 449 F1 Jupiter нагреванием образца в токе гелия, подаваемого со скоростью $40 \mathrm{~cm}^{3} \mathrm{c}^{-1}$, до конечной температуры $1000^{\circ} \mathrm{C}$. Морфологию образцов исследовали на электронном микроскопе HitachiTM-1000. Идентификацию кристаллических фаз в твердом продукте проводили на основе анализа дифракционной картины, регистрируемой дифрактометром ДРОН-3.

Вольтамперные зависимости твердых продуктов снимали на потенциостате P 30 SM, используя метод циклической вольтамперометрии. Развертка потенциала выполнялась по программе от компромиссного потенциала. Измерения проводили в стандартной трехэлектродной ячейке; в качестве вспомогательного электрода использована платиновая проволока; электродом сравнения служил насыщенный хлорсеребряный электрод ЭСр10101, что подробно описано в работе [16].

Сняты циклические вольтамперограммы (ЦВА) исследуемых образцов и рассчитана кажущаяся удельная емкость образца по формуле, предложенной в работе [17]:

$$
C_{\text {каж }}=\int_{U 0}^{U 1} I d U /(m \cdot v \cdot \Delta U),
$$


где $\mathrm{C}_{\text {каж }}$ - удельная емкость, пересчитанная на массу активного материала (исследуемого образца), $\Gamma^{-1} ; \mathrm{m}$ - масса активного электродного материала, г; $v$ - скорость развертки потенциала, $\mathrm{B} \cdot \mathrm{c}^{-1} ; \mathrm{I}$ - электрический ток в диапазоне напряжений $\Delta \mathrm{U}, \mathrm{A} ; \Delta \mathrm{U}$ - интервал напряжений, для которого проводится расчет удельной емкости, В.

\section{Результаты и обсуждение}

В процессе карбонизации исследуемых образцов выход твердого продукта с ростом температуры падает. Причем выход ТП из немодифицированных образцов составляет 25 мас. \% (при $400{ }^{\circ} \mathrm{C}$ ) и 19 мас. \% (при $800{ }^{\circ} \mathrm{C}$ ), а выход ТП из модифицированных образцов - 19 и 17 мас. \% при 400 и $800{ }^{\circ} \mathrm{C}$ соответственно. Таким образом, наименьший выход продукта наблюдается при карбонизации модифицированного образца, карбонизованного до $800{ }^{\circ} \mathrm{C}$.

Величина удельной поверхности ТП существенно зависит от наличия в образце модификатора. Так, если при $400{ }^{\circ} \mathrm{C}$ удельная поверхность ТП из ДО составляет всего $22 \mathrm{M}^{2} \cdot \Gamma^{-1}$, то удельная поверхность ТП из ДО- $\mathrm{ZnCl}_{2}$, полученного при той же температуре равна $1813 \mathrm{M}^{2} \Gamma^{-1}$. При температуре карбонизации $800{ }^{\circ} \mathrm{C}$ удельная поверхность немодифицированного продукта возрастает до $471 \mathrm{M}^{2} \cdot \Gamma^{-1}$, а модифицированного продукта несколько уменьшается - до $1077 \mathrm{M}^{2} \Gamma^{-1}$, по сравнению с продуктами, полученными при $400{ }^{\circ} \mathrm{C}$.

Таким образом, высокопористый продукт с удельной поверхностью до $1800 \mathrm{M}^{2} \Gamma^{-1}$ можно получить из модифицированной хлоридом цинка осины, причем низкотемпературная карбонизация $\left(400{ }^{\circ} \mathrm{C}\right)$ дает пористый продукт с более высокой удельной поверхностью, чем высокотемпературная карбонизация $\left(800^{\circ} \mathrm{C}\right)$.

Дифференциальный термический анализ образцов показал, что максимальная скорость деструкции (13\%'мин $\left.{ }^{-1}\right)$ исходной биомассы наблюдается при $360{ }^{\circ} \mathrm{C}$ (рис. 1).

Основное разложение композиционной смеси ДО- $\mathrm{ZnCl}_{2}$ происходит с меньшей интенсивностью (максимальная скорость составляет $4 \%$ мин $^{-1}$ ), однако такое разложение наблюдается в двух температурных интервалах; пики максимума приходятся на температуры 200 и $\sim 600{ }^{\circ} \mathrm{C}$.
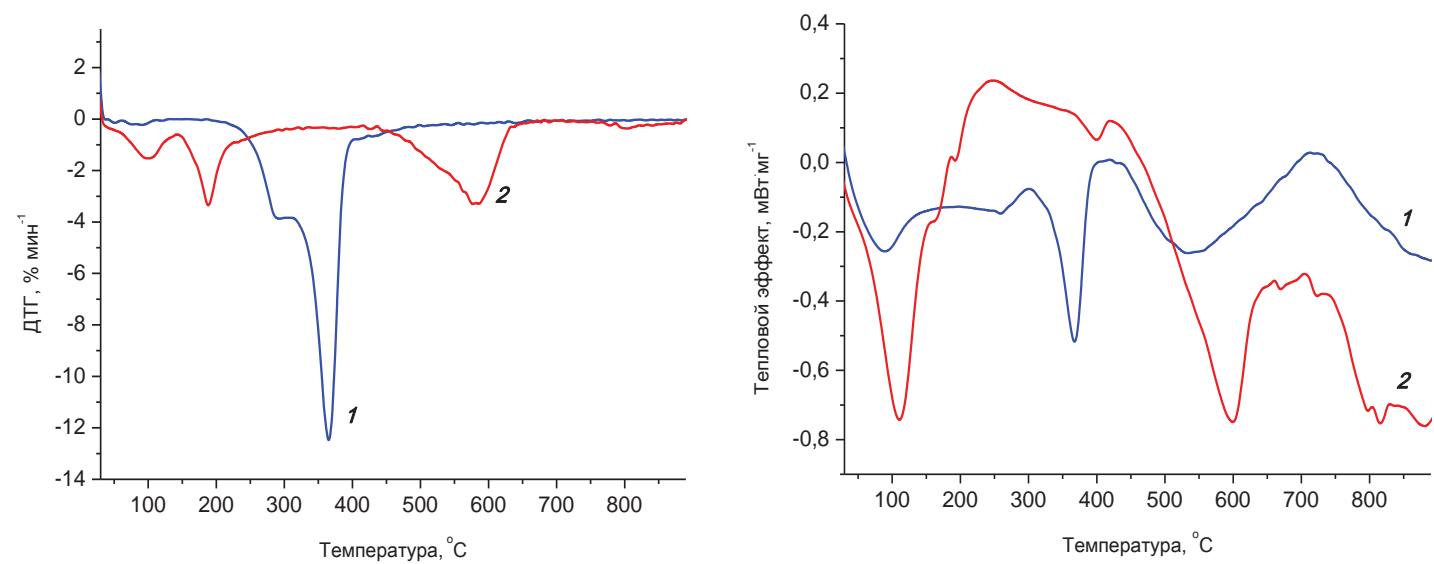

Рис. 1. ДТА образцов из исходных опилок осины (1) и модифицированных $\mathrm{ZnCl}_{2}(2)$

Fig. 1. DTA of samples from the aspen sawdust (1) and aspen sawdust with $\mathrm{ZnCl}_{2}$ (2) 
Для всех образцов наблюдается эндотермический эффект в интервале температур 30-145 ${ }^{\circ} \mathrm{C}$, который вызван, в основном, испарением прочно адсорбированной воды (рис. 1). Интенсивный термораспад древесины осины, наблюдаемый в области $300-400{ }^{\circ} \mathrm{C}$, протекает с эндотермическим эффектом, а заметное разложение модифицированного образца 2 в низкотемпературной области сопровождается переходным состоянием - доминирование процессов с эндоэффектом сменяется доминированием процессов с экзоэффектом. Деструкция их в высокотемпературной области сопровождается в основном эндотермическими процессами.

Подобное поведение модифицированных образцов можно объяснить образованием комплексов $\mathrm{H}^{+}\left[\mathrm{ZnCl}_{2} \mathrm{OH}\right]^{\prime}$, способных уже при $200{ }^{\circ} \mathrm{C}$ передавать протон бренстедовским основным центрам углеродсодержащих макромолекул [2] и катализировать образование карбоний-ионов, которые, в свою очередь, промотируют процессы деалкилирования углеродсодержащих соединений в низкотемпературной области. Дальнейшее повышение температуры до $500{ }^{\circ} \mathrm{C}$ приводит сначала к стабилизации радикалов, а затем к интенсификации процессов высокотемпературной поликонденсации и эмиссии газообразных продуктов.

На рис. 2 приведены снимки поверхности немодифицированных (a, b) и модифицированных (c, d, e) образцов до и после карбонизации. Как видим, нагрев исходных опилок до $800{ }^{\circ} \mathrm{C}$ незначительно влияет на текстуру поверхности продукта (рис. $2 b$ ).

Карбонизация модифицированных образцов приводит к потере текстурных следов, характерных для древесины; частицы становятся меньших размеров, более того, проявляется вторая фаза в виде мелких светлых частичек, микроанализ которых показывает, что они состоят в
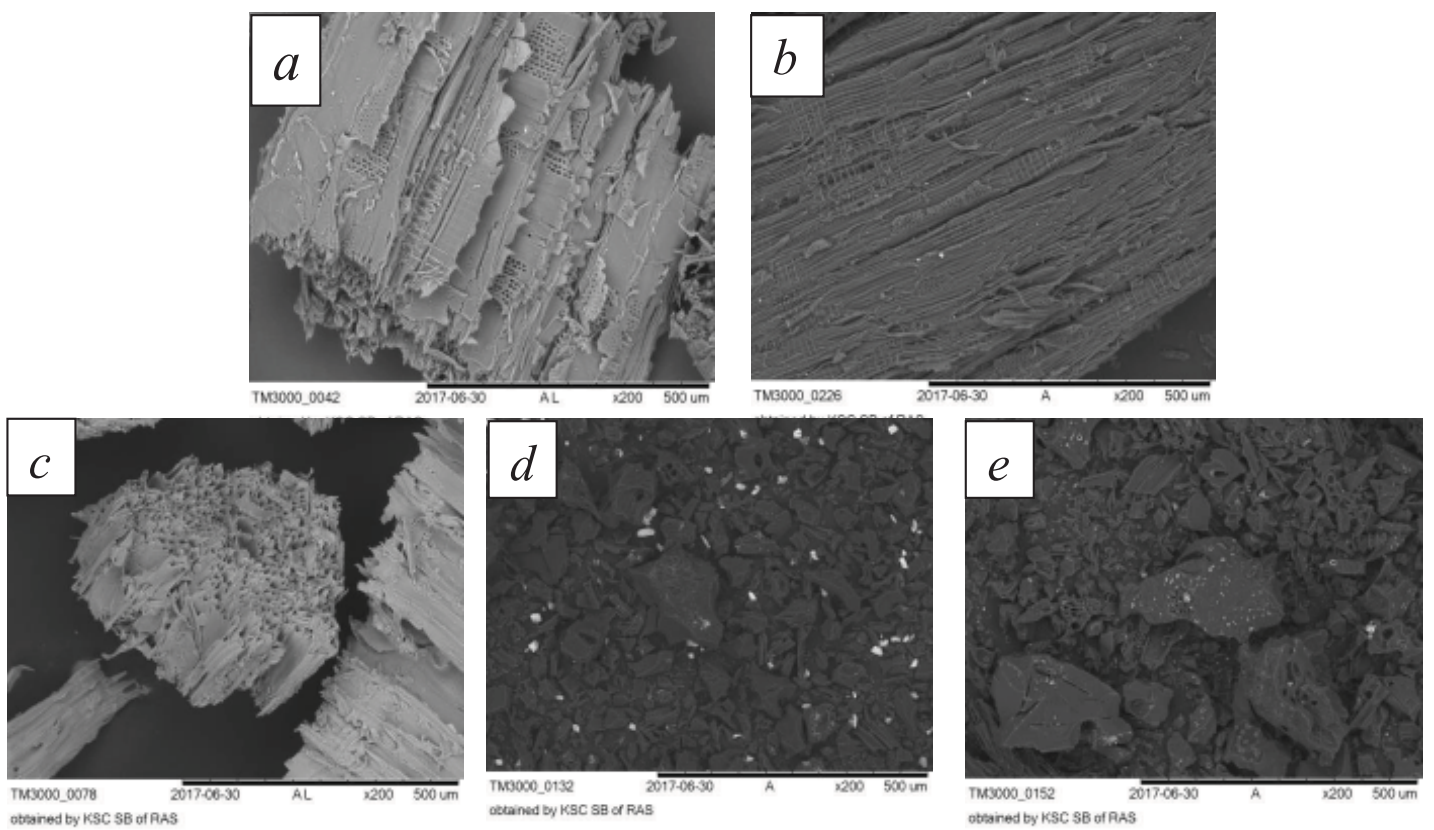

Рис. 2. Морфология поверхности карбонизованных немодифицированных $\left(\mathrm{a}-25{ }^{\circ} \mathrm{C}, \mathrm{b}-800{ }^{\circ} \mathrm{C}\right)$ и модифицированных $\mathrm{ZnCl}_{2}\left(\mathrm{c}-25^{\circ} \mathrm{C}, \mathrm{d}-400^{\circ} \mathrm{C}, \mathrm{e}-800^{\circ} \mathrm{C}\right)$ образцов

Fig. 2. Morphology of the surface of aspen $\left(\mathrm{a}-25^{\circ} \mathrm{C}, \mathrm{b}-800^{\circ} \mathrm{C}\right)$ and aspen modified with $\mathrm{ZnCl}_{2}\left(\mathrm{c}-25^{\circ} \mathrm{C}\right.$, $\left.\mathrm{d}-400{ }^{\circ} \mathrm{C}, \mathrm{e}-800^{\circ} \mathrm{C}\right)$ 
основном из оксида цинка. К тому же необходимо обратить внимание на то, что в образце, карбонизованном при $400{ }^{\circ} \mathrm{C}$, количество их заметно больше, чем в образце, карбонизованном при $800{ }^{\circ} \mathrm{C}$.

Дифракционные картины карбонизованных при различных температурах немодифицированных образцов (рис. $3 a$ ) практически идентичны и указывают на несущественное влияние температуры на структурные изменения. Наблюдаемое гало в области $\sim 23^{\circ}$ и $43^{\circ}$ характеризует аморфную составляющую углеродной фазы.

На дифрактограмме образца, полученного из модифицированной древесины при $400{ }^{\circ} \mathrm{C}$, можно увидеть две основные фазы - аморфно-кристаллическая структура углерода, о чем свидетельствует широкая интенсивная полоса в области 20-30, и структура $\mathrm{ZnO}$, интенсивные рефлексы которой наблюдаются в диапазоне углов 30-70 (рис. 3b). Дифрактограмма высокотемпературного образца имеет, в основном, полосы аморфного углерода. Низкоугловое интенсивное поглощение в области $10^{\circ}$ указывает на наличие гидроксокомплексов цинка в продуктах.

Таким образом, модифицирование осины хлоридом цинка приводит к существенным структурным изменениям твердых продуктов в процессе карбонизации, в результате чего существенно растет удельная поверхность продукта и формируется новая кристаллическая фаза $\mathrm{ZnO}$.

Известно, что пористый углерод и композиты, содержащие $\mathrm{ZnO}$, используются во многих электродных материалах, включая сенсоры и конденсаторы [7-12], поэтому представляло интерес изучить влияние процесса синтеза на электрические показатели полученных продуктов, используя метод циклической вольтамперометрии. Поскольку на емкостные характеристики электродных материалов может влиять концентрация электролита, то в данной работе были изучены вольтамперограммы образцов в электролитах 1М и $3 \mathrm{M} \mathrm{КОН.}$

На рис. 4 приведены циклические вольтамперограммы продуктов, снятые в диапазоне от -600 до 600 мВ. Как видим, форма кривых ЦВА существенно меняется в зависимости от типа
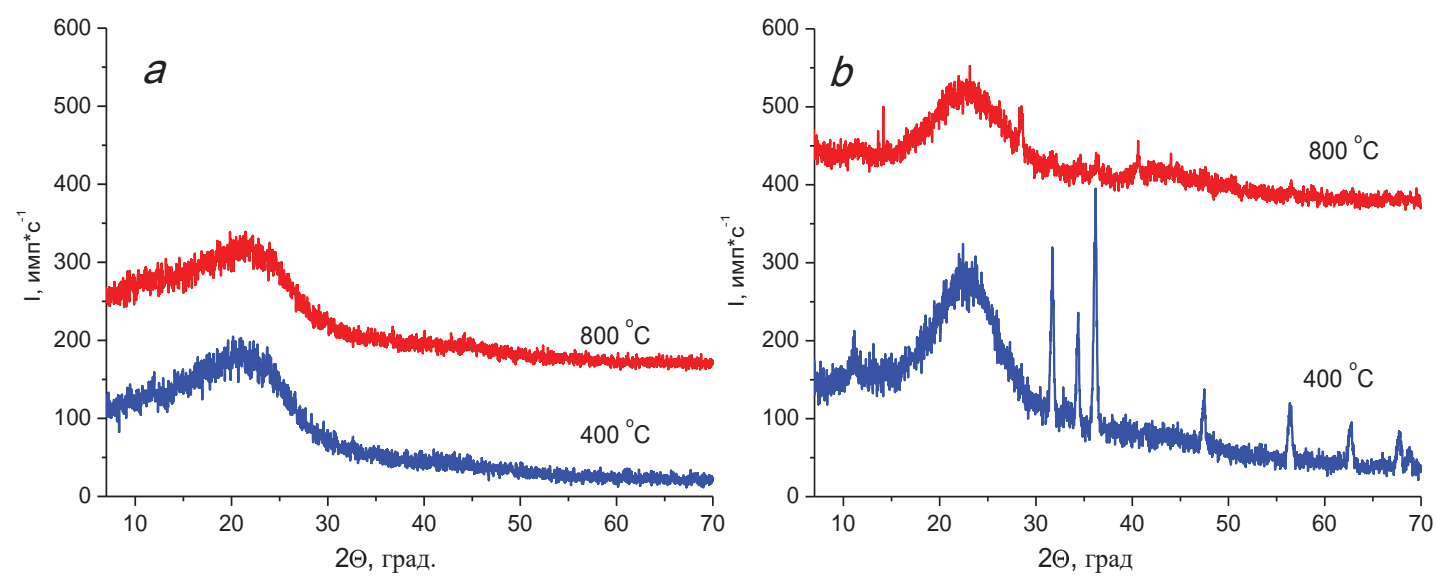

Рис. 3. Рентгенодифрактограммы твердого продукта, полученного из исходной (a) и модифицированной (b) осины при температурах 400 и $800^{\circ} \mathrm{C}$

Fig. 3. X-ray diffractograms of solid product obtained from the initial (a) and modified (b) aspen at temperatures of 400 and $800^{\circ} \mathrm{C}$ 

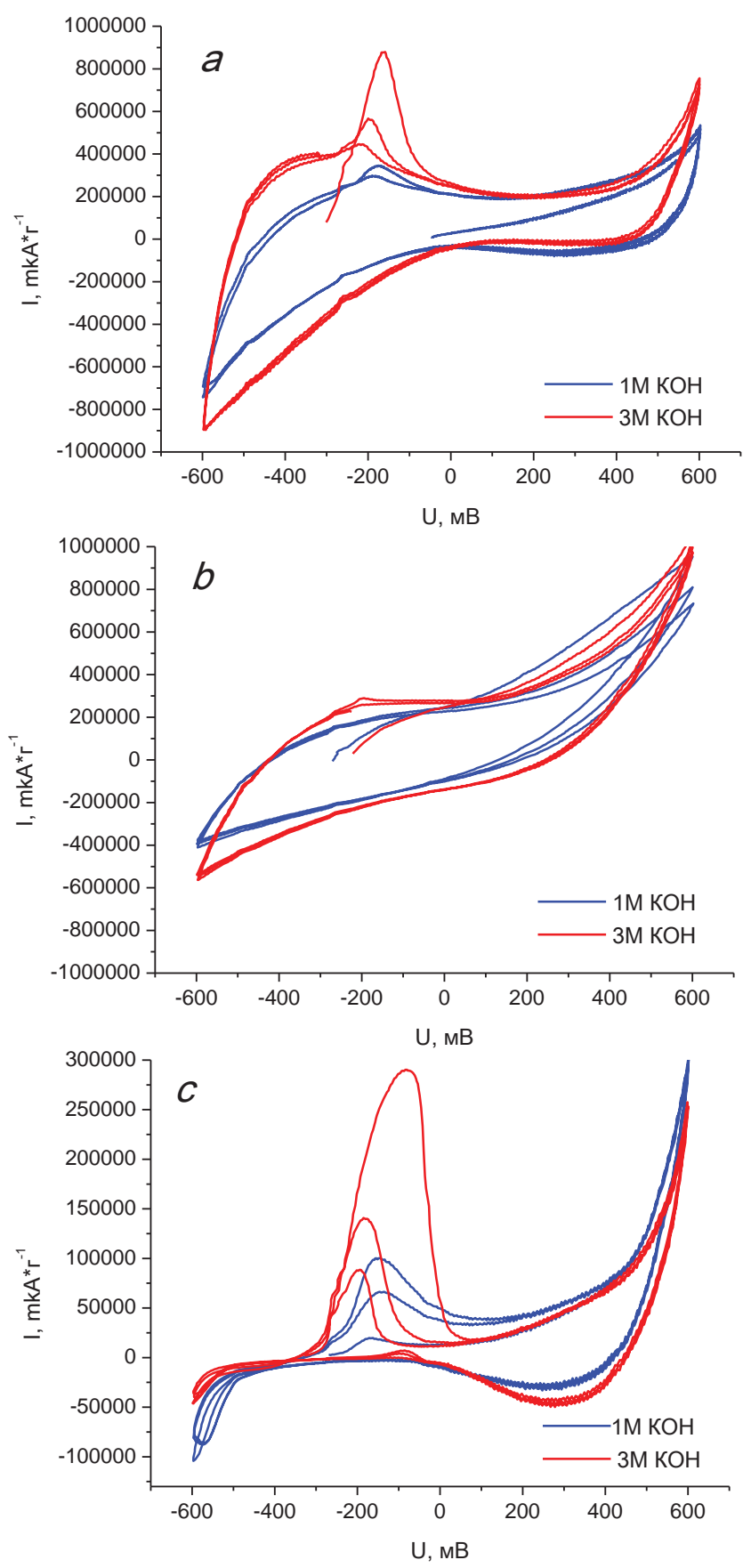

Рис. 4. Циклическая вольтамперограмма твердого продукта, полученного из: а - исходных опилок осины $\left(\mathrm{T}=800{ }^{\circ} \mathrm{C}\right) ; \mathrm{b}$ - модифицированных хлоридом цинка $\left(\mathrm{T}=800^{\circ} \mathrm{C}\right), \mathrm{c}-$ модифицированных хлоридом цинка $\left(\mathrm{T}=400{ }^{\circ} \mathrm{C}\right)$, при скорости развертки потенциала $10 \mathrm{MB} \cdot \mathrm{c}^{-1}$ в $1 \mathrm{M}$ и $3 \mathrm{M} \mathrm{KOH} \mathrm{электролитах}$

Fig. 4. Cyclic voltammogram of solid product obtained from: $\mathrm{a}-$ initial sawdust of aspen $\left(\mathrm{T}=800^{\circ} \mathrm{C}\right), \mathrm{b}-$ aspen modified with zinc chloride $\left(\mathrm{T}=800^{\circ} \mathrm{C}\right), \mathrm{c}-$ modified with zinc chloride $\left(\mathrm{T}=400^{\circ} \mathrm{C}\right)$, at the potential sweep rate of $10 \mathrm{mV} \cdot \mathrm{c}^{-1}$ in $1 \mathrm{M}$ and $3 \mathrm{M} \mathrm{KOH}$ electrolytes 
используемого материала и в меньшей степени от концентрации электролита. Так, для ДО, карбонизованной при $800{ }^{\circ} \mathrm{C}$, наблюдается рост проводимости материала с ростом потенциала в интервале от -600 до -100 мВ; дальнейшее повышение потенциала до 400 мВ практически не влияет на величину тока. В потенциальном окне от -200 до -100 мВ проявляется анодный пик, который существенно возрастает при использовании более концентрированного электролита $(3 \mathrm{M} \mathrm{KOH)} \mathrm{и} \mathrm{может} \mathrm{быть} \mathrm{вызван} \mathrm{окислением} \mathrm{карбоксильных} \mathrm{групп,} \mathrm{содержащихся} \mathrm{в} \mathrm{углерод-}$ ном продукте.

Циклическая вольтамперограмма для ДО- $\mathrm{ZnCl}_{2}$, карбонизованной до той же температуры, имеет fish-форму и показывает, что никаких существенных редокс-процессов не происходит, а образец ведет себя как типичная двухслойная электрическая емкость в потенциальном окне от -600 до 600 мВ. Необходимо отметить также, что концентрация электролита практически не влияет форму вольтамперограммы.

При использовании ДО- $\mathrm{ZnCl}_{2}$, карбонизованной до $400{ }^{\circ} \mathrm{C}$, на ЦВА кривых наблюдаются максимальные пики окисления в диапазоне потенциалов от -300 до 100 мВ, которые резко возрастают в ЗМ КОН электролите по сравнению с использованием одномолярного раствора. Это может быть обусловлено высоким содержанием оксида цинка в образце (рис. $3 b$ ), который необратимо взаимодействует с гидроксогруппой молекулы щелочи, в результате чего образуется тетрагидроксоцинкат(II) калия

$$
\mathrm{ZnO}+2 \mathrm{KOH}+\mathrm{H}_{2} \mathrm{O}=>\mathrm{K}_{2} \mathrm{Zn}(\mathrm{OH})_{4} .
$$

Ввиду того, что используемый материал является пористым и доступность к поверхностным группам высока, наибольший анодный пик наблюдается в первом цикле, при последующих циклах он резко падает, свидетельствуя об уменьшении окислительных центров в материале.

Ниже приведены ЦВА-кривые для этих образцов в узком диапазоне потенциалов 0-450 мВ (pис. 5). Как видим, в этом диапазоне потенциалов ЦВА для образцов ДО $\left(800{ }^{\circ} \mathrm{C}\right)$ и ДО- $\mathrm{ZnCl}_{2}$ $\left(400{ }^{\circ} \mathrm{C}\right)$ имеют псевдопрямоугольную форму, что является идентификатором двухслойной емкости с быстрыми заряд-разряд-скоростями. Кажущиеся удельные емкости при скорости развертки потенциала $10 \mathrm{MB} \cdot \mathrm{c}^{-1}$ составляют 415 и 220 Ф·Г-1д для ДО $\left(800{ }^{\circ} \mathrm{C}\right)$ и ДО- $\mathrm{ZnCl}_{2}\left(400{ }^{\circ} \mathrm{C}\right)$ соответственно.

Fish-форма ЦВА для ДО- $\mathrm{ZnCl}_{2}\left(800^{\circ} \mathrm{C}\right)$ в этом интервале потенциалов свидетельствует о том, что перенос электронов лимитируется диффузионными процессами адсорбции-десорбции ионов на границе раздела электрод/электролит.

Таким образом, для потенциального использования материала в электрохимическом конденсаторе важен не только состав исходного сырья для их получения, но и температура его синтеза. Псевдопрямоугольная форма ЦВА полученных продуктов свидетельствует о возможности использования данного материала в качестве конденсатора.

\section{Выводы}

1. Показано, что опилки осины могут быть успешно использованы для получения пористых углеродных электродных материалов. Выявлено, что на электрохимические свойства продукта влияет не только состав сырья для их получения, но и условия синтеза.

$$
-288-
$$




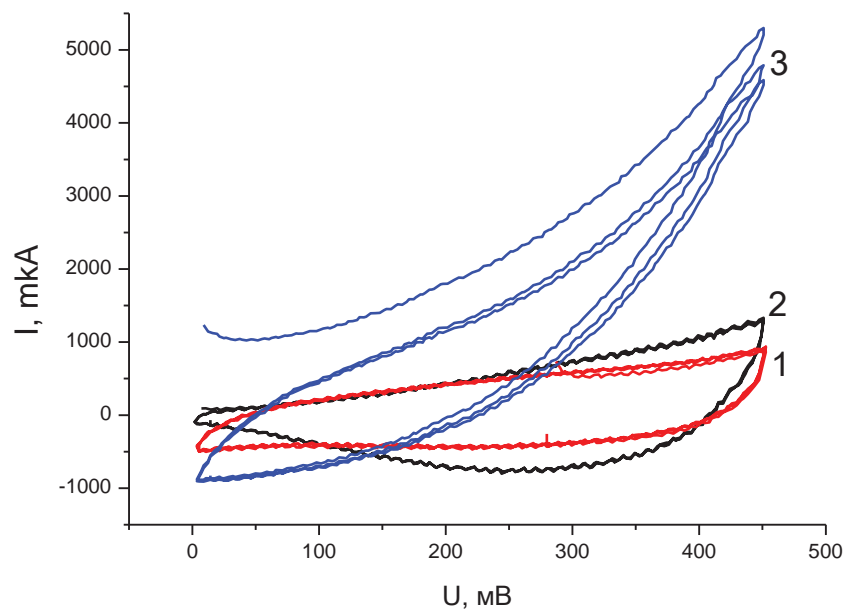

Рис. 5. Циклическая вольтамперограмма твердого продукта, полученного из: 1 - исходных опилок осины $\left(\mathrm{T}=800^{\circ} \mathrm{C}\right) ; 2$ - модифицированных хлоридом цинка $\left(\mathrm{T}=400^{\circ} \mathrm{C}\right) ; 3$ - модифицированных хлоридом цинка $\left(\mathrm{T}=800{ }^{\circ} \mathrm{C}\right)$, при скорости развертки потенциала $10 \mathrm{MB} \cdot \mathrm{c}^{-1}$ в $3 \mathrm{M} \mathrm{KOH} \mathrm{электролите;} \mathrm{диапазон} \mathrm{потенциалов}$ $0-450 \mathrm{MB}$

Fig. 5. Cyclic voltammogram of solid product obtained from: 1 - initial sawdust of aspen $\left(\mathrm{T}=800{ }^{\circ} \mathrm{C}\right) ; 2-$ modified with zinc chloride $\left(\mathrm{T}=400{ }^{\circ} \mathrm{C}\right) ; 3-$ modified with zinc chloride $\left(\mathrm{T}=800{ }^{\circ} \mathrm{C}\right)$, at potential sweep rate $10 \mathrm{mV} \cdot \mathrm{c}^{-1} \mathrm{in}$ the $3 \mathrm{M} \mathrm{KOH}$ electrolyte; potential range $0-450 \mathrm{mV}$

2. Установлено, что карбонизация смеси опилок осины с хлоридом цинка приводит к образованию высокопористого оксид цинка/углерод продукта с удельной поверхностью до $1800 \mathrm{M}^{2} \cdot \Gamma^{-1}$.

3. Выявлено, что в процессе карбонизации смеси опилок с хлоридом цинка образуются две фазы: аморфная структура углерода и кристаллиты оксида цинка.

4. Изучение электрохимических свойств полученных продуктов с помощью циклической вольтамперограммы показало, что они могут вести себя как электрохимические конденсаторы в диапазоне потенциалов 0-450 мВ. Выявлено также, что содержание кислородсодержащих групп в углеродной матрице и оксида цинка в продукте приводит к необратимым окислительным процессам в потенциальном окне от -300 до 100 мВ.

\section{Благодарности}

В работе использованы приборы центра коллективного пользования Федерального исследовательского центра «Красноярский научный центр СО РАН».

\section{Список литературы}

1. Marsh H., Rodriguez-Reinoso F. Activated carbon. Elsevier Ltd., 2006. 536 p.

2. Фенелонов В.Б. Введение в физическую химию формирования супрамолекулярной структуры адсорбентов и катализаторов. Новосибирск, Изд-во СО РАН, 2002. 414 c. [Fenelonov V.B. Introduction in physical chemistry of the formation of supramolecular structure of adsorbents and catalysts. Novosibirsk, SB RAS, 2002. 414 c. (In Russ.)]

3. Цыганова С.И., Чесноков Н.В., Кузнецов Б.Н. Изучение карбонизации древесины березы и осины, модифицированной взрывным автогидролизом и добавками $\mathrm{ZnCl}_{2}$. Журнал Сибир-

$$
-289-
$$


ского федер)ального университета. Химия 2015. T. 1(8), C. 92-98. [Tsyganova S.I., Chesnokov N.V., Kuznetsov B.N. Study of the carbonization of birch and aspen wood modified by explosive autohydrolysis and $\mathrm{ZnCl}_{2}$. additives. Journal of Siberian Federal University. Chemistry 2015. Vol. 1 (8), P. 92-98. (In Russ.)]

4. Tsyganova S.I., Bondarenko G.N., Korol'kova I.V., Fetisova O.Yu., Kargin V.F., Velikanov D.A. Synthesis of a highly porous carbon material with magnetic properties. Russian Journal of Applied Chemistry 2011. Vol. 84 (12), P. 2131-2136.

5. Derbyshire F., Jagtoyen M., Andrews R., Rao A., Martin-Guillon I., Grulke E. Carbon materials in environmental applications. Chemistry and physics of carbon 2001. Vol. 27, P. 1-66.

6. Гиндулин И.К., Юрьев Ю.Л. Термохимическая переработка осиновой древесины. Becmник технологического университета 2017. T. 20 (4), C. 31-32. [Gindulin I.K., Yuriev Yu.L. Thermochemical processing of aspen wood. Bulletin of the Technological University 2017. Vol. 20(4), P. 3132 (In Russ.)]

7. Choi H., Yoon H. Nanostructured electrode materials for electrochemical capacitor applications. Nanomaterials 2015. Vol. 5, P. 906-936.

8. Mohapatra D., Parida S., Badrayyana S., Singh B.K. High performance flexible asymmetric $\mathrm{CNO}-\mathrm{ZnO} / / \mathrm{ZnO}$ supercapacitor with an operating voltage of $1.8 \mathrm{~V}$ in aqueous medium. Applied Materials Today 2017. Vol. 7, P. 212-221.

9. Xia Y., Wang J., Chen R., Zhou D., Xiang L. A review on the fabrication of hierarchical ZnO nanostructures for photocatalysis application. Crystals 2016. Vol. 6, P. 2-19.

10. Yakimova R., Selegård L., Khranovskyy V., Pearce R., Lloyd Spetz A., Uvdal K. ZnO materials and surface tailoring for biosensing. Frontiers in bioscience 2012. Vol. 4, P. 254-78.

11. Marie M., Mandal S., Manasreh O. An electrochemical glucose sensor based on zinc oxide nanorods. Sensors 2015. Vol. 15, P. 18714-18723.

12. Aravinda L.S., Nagaraja K.K., Nagaraja H.S., Udaya B.K., Ramachandra B.B. ZnO/carbon nanotube nanocomposite for high energy density supercapacitors. Electrochimica Acta 2013. Vol. 95, P. 119-124.

13. Sidhu N.K., Rastogi A.C. Vertically aligned $\mathrm{ZnO}$ nanorod core-polypyrrole conducting polymer sheath and nanotube arrays for electrochemical supercapacitor energy storage. Nanoscale Research Letters 2014. Vol. 94 (53), P. 2-16.

14. Guetteche Y., Bordjiba T., Bouguerne B., Nabeti Z., Mahmoudi O., Lemzademi A. Development of composite material based on porous microfibrous carbon and zinc oxide for energy storage application. Int. J. Electrochem. Sci. 2017. Vol. 12, P. 1874-1884.

15. Sivakumar M., Sakthivel M., Chen S.-M. Activated carbon-ZnO nanocomposite for electrochemical sensing of acetaminophen. Int. J. Electrochem. Sci. 2016. Vol. 11, P. 8363-8373.

16. Цыганова С.И., Романченко А.С., Бондаренко Г.Н., Фетисова О.Ю. Синтез углеродсодержащего композита на основе древесины осины. Журнал прикладной химии 2018. Т. 91 (2), C. 40-47 [Tsyganova S.I., Romanchenko A.S., Bondarenko G.N., Fetisova O.Yu. Synthesis of carbon-based composites based on aspen wood. Journal of Applied Chemistry. Vol. 91(2), P. 40-47. (In Russ.)]

17. Raghu M. Nanostructured arrays for sensing and energy storage applications. University of Kentucky doctoral dissertations. 2011, 153 p. 